\title{
Skating in the Sun:
}

\section{Examining Identity Formation of National Hockey}

\section{League Fans in Sunbelt States}

\author{
Brandon Mastromartino - University of Georgia \\ Daniel L. Wann - Murray State University \\ James J. Zhang - University of Georgia
}

\begin{abstract}
As the National Hockey League (NHL) has made concerted efforts in recent years to expand into the Sunbelt region of North America, its teams still face tremendous challenges to building up their fan bases. Adopting a qualitative research protocol, this study explored the phenomenon of NHL fandom formation in the Sunbelt region. Research findings revealed key patterns and trends that influenced individuals to become fans of NHL teams in this strategic region of growth. A discussion of socialization into fandom was developed based on the themes and assertions derived in the study, which suggested that the fan community would play a significant role in fan identity formation and be a major driving force in the league's market penetration into new marketplaces. The findings offer practical implications for teams to build and expand their fan bases and also provide a foundation for future quantitative investigations.
\end{abstract}

Keywords: Sports marketing, consumer behavior, fan identification, fan socialization, national hockey league.

\author{
Research Article, Sport Marketing \\ Journal of Emerging Sport Studies \\ Volume 2, (2019): London, Ontario
}

All Rights Reserved, 2018: ISSN - 2562-3184 


\section{Introduction}

Professional sports in North America grew exponentially throughout the $20{ }^{\text {th }}$ century. However, approaching the third decade of the new millennium, this growth seems to have reached the point of saturation (Gaines, 2013). Coupled with the dominance of three professional leagues (NFL, NBA, and MLB) and collegiate athletics, other professional sport leagues face tremendous challenges in expanding their brands and developing new fans. In this competitive climate, a solution for less established leagues, such as Major League Soccer (MLS) or the National Lacrosse League (NLL), is to bring their leagues to geographical areas of the United States where there is not a long tradition of that particular sport in an effort to develop new fan basses in an untapped market environment. To accomplish this, sport organizations need to understand how the fan identity formation process occurs in a new market context where a sport or league does not yet have a footprint. For example, the National Hockey League (NHL) utilized a strategy in the early 90s by expanding to the southern United States. Through the examination of the NHL's expansion to the Sunbelt states as a case analysis, this study aims to develop a conceptual model whereby professional sport franchises can better understand the fan identity formation process for teams in a new or non-traditional marketplace.

The business of the NHL has been riding a wave of momentum in recent years, as revenues grew from $\$ 2.2$ billion in the late 1990s to approximately $\$ 4.0$ billion in 2014 (Thomas, 2014). In June 2016, the NHL announced the addition of an expansion team in Las Vegas, Nevada, which started in the 2017-2018 season. Las Vegas is considered part of the Sunbelt region, a geographic region that is generally thought to stretch across the Southeastern and Southwestern U.S. In addition to Las Vegas, there are nine other NHL teams in this region: Anaheim Ducks, Arizona Coyotes, Carolina Hurricanes, Dallas Stars, Florida Panthers, Los Angeles Kings, Nashville Predators, San Jose Sharks, and Tampa Lightning. The beginning of the NHL's south-bound movement coincided with the start of current NHL commissioner Gary Bettman's tenure in 1993. It was a significant time for the NHL teams, as they were heading into a labor dispute between owners and players, resulting in a shift in the economics of hockey. As a result of the new collective bargaining agreement (CBA) in 1995, player salaries became public information and player agents were able to compare the performance of their clients to other players; consequently, they demanded similar financial compensations, causing player salaries to skyrocket. In the meantime, this critical juncture has led the NHL to gradually transform from a small-time league to major players among North American professional sport leagues (Jenish, 2013). Looking for new ways to expand its market influence and increase revenue, the NHL set its sights on developing new franchises, with a priority on major media markets to gain television viewership and strike a large national television deal. In the early $90 \mathrm{~s}$, the NHL started to expand for the first time since its merger with the World Hockey Association in 1979. San Jose entered the league in 1991, Tampa Bay in 1992, Anaheim and Florida in 1993, and Minnesota relocated to Dallas in the same year. The NHL continued its southern expansion a few years later when Winnipeg relocated to Phoenix in 1996; Hartford relocated to Raleigh, North Carolina, in 1997; and Nashville and Atlanta received expansion teams in 1998 and 1999. Over a span of 10 years, the NHL expanded from one team in the Sunbelt region to 10 teams. The choices of these new locations were unconventional but clearly intentional, due to the size of the media reach in those markets. 
The hockey fandom in the Sunbelt region appears to be unique. Exposure to the sport of hockey is fairly new in the Sunbelt states. Local ice rinks in these areas were few and far between 20 years ago, which made playing and learning about the game of hockey difficult. Even when ice rinks are present in local communities, it is still very expensive to engage in this sport, due to the costs of equipment, ice time rental, and travel to other community teams. With the intention to enhance motivation for individuals to attend games and ultimately increase their levels of identification, fandom, and commitment, NHL teams in the Sunbelt region have made efforts to have a presence in the community through organizing outreach activities, community events, youth hockey camps, and grassroots promotions. In this region, the unique consumer base, local culture, and new hockey environment all contribute to the challenges in developing a fan's identity. How and why does a fan identify with a hockey team in this region? Are these fans the same as, or different from, their counterparts in the North? Little research has been done to date to answer such questions about this unique phenomenon.

Previous researchers have shown that sport fan identification predicts motivations to attend games and consume team-related products (e.g., Sutton, McDonald, Milne, \& Cimperman, 1997). Fan identification leads to emotional attachment, which then leads to behavioral responses of consumers to team performance and marketing activities. Supportive behaviors include going to games and events, buying team related merchandise, and consuming team media, which are the primary sources of revenue for sport organizations. The more identified fans are, the more they consume and, consequently, the more the organization will profit. As there are varying levels of fan identification, different factors may influence how one views him- or herself as a fan of a particular sport and team (Wann \& James, 2018). Understanding the origin and reinforcement of sport identification is important for sport teams to develop campaigns and programs to attract, nurture, strengthen, and sustain consumer allegiance and commitment. Nonetheless, although some studies have been conducted to examine the relevance of hockey fan consumption behavior (Mastromartino, 2019), sport fan identification (Wann, 2006), or motivation for spectators to attend sporting events (Trail \& James, 2001) less is known about how an individual forms a social identity in a spectator sport, particularly when considering the unique dynamic of the NHL in new and non-traditional market environments.

The purpose of this research was to identify, through a qualitative inquiry, factors that have led individuals to identify with NHL teams in the Sunbelt region of the United States. The derived information would allow for a greater insight into professional hockey located in an unconventional marketplace and the potential to grow the NHL in new areas. Learning what factors contribute to the formation of an individual's strong identification with a team in this region would allow the NHL teams to create a larger and stronger fan base and to build robust traditions and cultures that are typically associated with fans of teams located in the North. Moreover, other professional sport leagues in North America could adapt the model as they attempt to expand in the shadow of the NFL, NBA, and MLB. 


\section{Theoretical Background}

\section{Social Identity Theory}

Social identity theory (Tajfel, 1978) should be considered when examining sport fans' identification with teams. Social identity is part of an individual's concept of him- or herself that comes from membership in one or more social groups and the value associated with this group membership. Individuals create a shared social identity through membership in social groups, such as a sport team's fan base, and subsequently internalize the values and beliefs of the social group as their own.

Underwood, Bond, and Baer (2001) argued that sport marketers do not maximize customer identification strategies to fully grow their brands. Their research highlighted areas in which sport franchises could build brand awareness, image, and loyalty to achieve financial success, regardless of the team's win-loss record. Four elements were recognized as fundamental characteristics through which the sport environment can promote social identity: (a) the group experience, (b) history and tradition, (c) the role of the physical facility, and (d) group or association rituals. The group experience in sport can represent a unique form of involvement characterized by a sense of belonging that group members feel, as well as an inherent prejudice against out-group members. Many organizations integrate the team's history into their core branding strategies, as many sport teams have unique traditions and use the nostalgia of days past to promote the current team. However, such history-based strategies are associated with teams who have long-established roots and celebrated winning records, making it challenging for NHL teams in the Sunbelt states to use this method of developing fan identity. Heere and James (2007) concluded that sport organizations could go beyond the fan identity of their supporters and capitalize on the external social identities of their fan base to strengthen their identity as a fan. The researchers suggested that finding the key external identities (such as demographic categories or other membership organizations) and aligning them with the team's positioning would lead to the fan base developing a stronger sense of identity as fans and, in turn, increase loyalty and consumption behavior related to the team. Associating external social identities with the team's image work s to build a sense of community among fans.

Muniz and O'Guinn's (2001) concept of brand community highlights how social identity is integral to the sport fan experience. Brand community refers to a community of individuals formed on the basis of its members' attachment to a product. In the case of sport, this product is a particular sport, team, and/or athlete. This concept suggests that a company's brand can grow stronger based on consumers' interactions with each other and with the community they build together, which is centered on their common identification with a company or product. Research on the effectiveness of brand communities has shown that strong brand communities lead to increased consumer-brand identification and increased consumption (Cova \& Pace, 2006; Schau, Muniz, \& Arnould, 2009). In a study on sport fans specifically, Yoshida, Heere, and Gordon (2015) found that attachment to the fan community explained the largest amount of variance within identity. Noticeably, fan-community attachment was the only factor that was found to be significantly predictive of continued attendance throughout the year. Social identity theory and research on brand communities show that the community fans build among themselves creates a stronger identity as a fan and is just as important to establishing a strong fan base as the actions taken by the organization. 


\section{Socialization and Identity Formation}

The current investigation targeted the origin of fan identity and factors that contribute to the process of hockey fan socialization and identity formation. Identity origin is important because sport fans reinforce identification with the team by engaging in supportive consumption behaviors. Sport fans in the southern United States have a long history of enjoying sports such as baseball, football, and motor sports. However, it is less clear how and why such people choose to identify with a new hockey team, despite the more prominent history of other sports in the region and the market competitions surrounding that team. Most NHL teams in the Sunbelt states are no more than 25 years old and thus, many of their fans may not have been 'born into' the hockey fan community like fans in the North.

According to Wann and James (2018), identity formation starts with socialization. Those factors that contribute to identity formation are called socialization agents. Sport fan socialization "occurs when we learn about the attitudes, values, and actions related to specific sport objects" (Wann \& James 2018, p. 30). The socialization of a fan often occurs in the early stages of an individual's cognitive development, as early as the age of five, but may not show the behaviors associated with team identification until later in life (James, 2001). McPherson (1976) conducted one of the first studies on sport fan socialization and concluded that an individual's family, peers, and community were the main influences on his or her socialization process in a participant sport. Frederiksen (2003) expanded on McPherson's ideas (1976) by adding another socialization agent - mass media. However, these studies had a general focus on participant sports and may not be applicable to the unique phenomenon of NHL spectators in the Sunbelt region.

Funk and James (2001) suggest that sport fans form a social identity by going through stages of their Psychological Continuum Model, the first stage being awareness. This stage is often brought about through the influence of the significant people in one's life. At a young age, often the most significant people in one's life are his/her parents and they can make a large impact in forming one's social interests, including sport fandom. Research by McPherson (1976); Parry, Jones, and Wann (2014); and Wann, Tucker, and Schrader (1996) all show how influential parents are when it comes to their children's sport fandom choices and behaviors. Parents influence their children through having games on television at home, purchasing merchandise, or enrolling their children to participate in that sport. One of the earliest studies that examined the effects of motivations of sport participation and level of sport spectatorship was Shamir and Ruskin (1984). The researchers identified similarities and differences for motivation in participation and spectatorship but did not examine the influence of sport participation on spectatorship and fan behaviors. Other examples of the relationship between past playing experience and consumption of that sport as a fan can be found in Greenwell, Fink, and Pastor (2002), Gwinner and Swanson (2003), and Tokuyama and Greenwell (2011). This previous research provides a solid understanding of the socialization process and sport fan identity, but there remains a gap in understanding identify formation in new or non-traditional markets in research, which this study aimed to fill.

Wann, Tucker, and Schrader (1996) identified many reasons for sport identification. They surveyed college students and asked them why they originally began and continued to follow their current favorite sport team. Participants were also asked to list the reasons why they stopped following a formerly favorite team. The five most common reasons for originally following their team were 1) because their 
parents were supporters of the team, 2) the talent and characteristics of the individual players, 3) geographical reasons for wanting to support the local team, 4) the influence of friends and peers, and 5) the success of the team. The fifth item on the list, the success of the team, was the participants' most common response when asked why they continue to support the team, while a lack of success was cited as the main reason for discontinuing their identification with a formerly favorite team. Wann et al.'s study shows that team success can be important in maintaining one's identity but not necessarily important in initially gaining that identity. Similar findings from Lock, Taylor, and Darcy (2011) concluded that self-esteem boosts from team success were less important for individuals developing an identity as a fan of a team new to the market. The researchers found that a strong desire to support the sport, civic pride, and the excitement aro und attending games were the most relevant factors for individuals socializing into fandom of a new football team in an Australian league. Doyle, Lock, Funk, Filo, and McDonald (2017) found that fans of new, unsuccessful teams were able to form and maintain an identity as a fan through developing a distinct in-group status by 'owning' their team's failure and focusing on a promising future for the team. Although there are some studies that focus on identity formation for fans of new teams, these studies suggest there is more work to be done: "Subsequent research should also observe fans in different sport environments and in a range of countries...such research could investigate new and rebranded US franchises..." (Doyle et al., 2017, p. 194). There is an apparent gap in the literature regarding how the socialization process occurs for sport fans where the team is new to that market and specifically, where the team and sport are new to that market.

There is a good understanding of what motivates individuals to socialize into sports and identify with a sport team in general; however, few studies have focused on how those motivations manifest in new or non-traditional sport markets. Some research has focused on fan identify formation in new markets (Doyle et al., 2017; Lock, Taylor, \& Darcy, 2011) but these previous studies were limited in their scope and suggested further research should be conducted in different contexts. In particular, there is an apparent void in the research on how individuals become sport fans, especially pertaining to fans of NHL teams in the Sunbelt region. Although the size of the fan base in the Sunbelt region may be smaller than that of teams in Canada or the Northern U.S., the presence of professional hockey could have some influence in the Sunbelt region being the fastest-growing area for youth hockey players (Klein, 2011). In light of the number of NHL teams, as well as the growing interest in youth hockey in the southern region, it is more important now than ever to evaluate the fan culture of NHL teams in the Sunbelt states and how the NHL and the game of hockey can continue to grow in this region.

No previous studies have been conducted to examine how NHL fans are socialized into being a fan of a team, especially in a growing area like the Sunbelt. Not enough is known about how self-identity and social identity form for a sport fan, particularly when considering the unique dynamics of the NHL in new and non-traditional marketplaces like the Sunbelt region. As these teams are relatively new compared to those in Canada and the Northern U.S., it is likely that fans of these teams may experience different socialization processes than fans of teams in regions more traditionally associated with hockey. Meanwhile, it is intriguing to see that, despite being in newer hockey market environments, a majority of the NHL teams in the Sunbelt region still have a sizeable fan base made up of highly identified fans. What, then, contributes to their identification as a fan? 


\section{Method}

This qualitative study was based on the consideration that there is a general lack of theories and empirical evidence on the originality and formation of sport fan identification. This study was intended to focus on an individual's 'lived experience' as a sport fan. According to Miles, Huberman, and Saldana (2014), qualitative data is "fundamentally well suited for locating the meanings people place on the events, processes, and structures of their lives and for connecting these meanings to the social world around them" (p. 11). The goal of this investigation was to learn about NHL fans in the Sunbelt region and how they make meaning of their fandom in the non-traditional hockey setting in which they live. 'Lived experience' in this case refers to the socialization process the individuals undergo, as well as the time spent as fans, that leads to their fan identity.

To achieve the stated objectives, a case study was conducted. The case study method was the most effective for gaining this understanding because it "is an empirical inquiry that investigates a contemporary phenomenon within its real-life contexts, especially when the boundaries between phenomenon and contexts are not clearly evident" (Yin, 2013, p. 13). The examination of a specific region, such as the Sunbelt, warrants a case study because the context for the NHL to establish a fan base in this region can differ from that of other regions of North America. While various forms of qualitative studies usually involve a small sample size, case study research has been proven to be a potentially suitable method for theory building (Siggelkow, 2007). Because the Sunbelt is a newer region for NHL hockey, the context of fan identification is not clearly evident and a case study approach can help researchers to recognize and define the constructs, boundaries, parameters, and process of identity formation that NHL fans undergo in the Sunbelt region specifically. This study followed guidelines from Tracy (2010) in order to ensure quality research. These guidelines included conducting the research process intentionally, with eight quality markers in mind. These quality markers include a worthy topic, rich rigor, sincerity, credibility, resonance, significant contribution, ethics, and meaningful coherence. These markers were followed closely and are primary tenants of this current investigation.

\section{Data Collection}

Data was collected and triangulated through interviews, archival documents, and in-person visits and attendance at games of the NHL team cities in the Sunbelt region. Interviews were the primary source of data for this research project. According to Rubin and Rubin (2012), qualitative interviewing produces highly credible results and "every conclusion is tightly linked to solid evidence, all embedded in a context" (p. 64). This study interviewed 20 individuals who identified themselves as fans of NHL teams in the same region. These numbers were chosen after research reached saturation. This is when no new information or themes were observed in the data (Miles et al., 2014). This approach featured an extended conversation between the primary researcher and the interviewee, for which the researcher prepared a number of questions in advance and asked follow-up questions (Rubin \& Rubin, 2012). The data from the interviews was supplemented by available literature and theories about motivation to consume sport, self and social identity, and the socialization and identity-formation process. Due to geographical limitations, interviews were 
primarily conducted via telephone or videoconferencing. All interviews were conducted throughout the 2015-2016 NHL season.

Fans were recruited to participate via postings on popular hockey fan online communities within the online community reddit.com. Phua (2010) conducted a study with the goal of finding a relationship between highly identified sport fans and whether and how much they consumed sport media, as well as identifying what medium they used most often. The research concluded that the more strongly one identified with a sport team, the more likely it was that he or she would consume sport media and online media. From Phua's study, it could be suggested that online communities of NHL teams in the Sunbelt would be a good place to find highly identified fans willing to participate in the study. Reddit.com was chosen because it is the ninth most visited website in the United States on a daily basis (Competitive Intelligence, 2016) and each NHL team has a subsection on the website, called a 'subreddit', dedicated to discussion around that team. At the time of the study, each team's subreddit had 1,700-10,000 subscribers and the general hockey subreddit had more than 240,000 subscribers. The large number of visitors and subscribers in the reddit online community provided an accessible venue to attract a diverse sample for this study. Although there is solid reasoning for recruiting fans online, it presents a limitation to the study in that fans who do not participate in online communities are not represented and whose values may not be reflected in the findings. However, due to the geographic restrictions in having participants from all over the country, online recruitment was the best available method for this study. Interviews with fans were conducted through Skype. During the interview, demographic information was collected and the interviewer turned to more indepth, open-ended questions about each interviewee's team identification, such as how he or she became a fan of the team, what kept him or her motivated to be a fan, and what he or she saw for the future of their identity as a fan. These standard questions were asked of all interviewees; however, individual anecdotes volunteered by participants were also included and were not replicated by every participant. In addition, the follow-up questions differed for each participant depending on their initial answers.

\section{Data Analyses}

Analyses occurred concurrently with the data collection, allowing the investigators to cycle back and forth between thinking about the existing data and generating strategies for new and possibly better data. This approach allowed for the possibility of collecting new data to fill in gaps found in the emerging data (Miles et al., 2014). Interviews were recorded with an audio device and were then transcribed following the transcription guidelines and techniques from Miles et al. (2014) and Rubin and Rubin (2012). To protect their identities, participants were assigned pseudonyms. The computer software programs ExpressScribe and ExpressDictate were used to assist with the transcription of the interviews and related transcripts were then sent to each of the participants to confirm their accuracy. Next, the information was uploaded to the Computer Assisted Qualitative Data Analysis Software ATLAS.ti to organize the data and to help identify key themes and patterns. Using Miles et al.'s (2014) procedures as a guide, an inductive two-level open coding process was adopted to identify overarching themes without a predetermined list. The first cycle of coding consisted of selecting words and phrases associated with specific categories or descriptions of the data, such as 'socialization process' or 'fan activities.' The second cycle focused on narrowing down the 
first order codes into more specific codes. Some examples of codes from the second cycle included "influence from parents" or "team performance" under "socialization process" and "purchasing merchandise" or "evangelism" under "fan activities." Because the current research topic has seldom been addressed in prior qualitative research, inductive coding was the primary method of coding used, while some other codes from established studies were used to support the current analyses. Moreover, the primary researcher attended four live games, visited the cities and arenas of two others, and was able to crossreference the collected data with personal experience and allowed for a deeper and extensive coding process.

\section{Findings}

The data collection process led to many relevant themes and patterns. Findings from the NHL fans focused on their socialization process as fans and the outcomes that led them to maintain their team identification. Interviews were conducted with 20 fans of the nine teams in the Sunbelt region. At the time of this research, the Vegas Golden Knights had not yet played their first game; thus, fans of the Golden Knights were not included in this study. Each team was represented by at least one fan participant; a full profile of participants can be found in Appendix A. All of the participants self-reported as highly identified fans of their respective NHL teams and spoke about how they became socialized into their fandom and the outcomes that solidified and maintained their membership in the fandom. These findings are organized by how each individual was socialized into fandom (team, personal, and media) and then how that fandom influences their fan behavior (fan identity maintenance).

\section{Socialization into Fandom}

\section{Influence from the team}

Often, a participant's first game experience occurred because a parent or friend took him or her to a game, but it was the game experience itself that was cited as a major factor for an individual becoming a lifelong fan of a team. For example, Noah mentioned the party atmosphere at the American Airlines Center as a reason for his team identification: "I went to one game and the arena was like a party. The music selection was off the wall, the DJ was a really cool guy, he takes pictures with everybody". Amy attended her team's first game in Nashville and Austin his team's first game in North Carolina; both felt that they were a part of something special because they attended one of the very first games in the organization's history. For Austin, it was a special night:

They played their first game October 29, 1999 against New Jersey. So that was also kind of a big deal because my dad, at the time was still a Devils fan, since we didn't know the Hurricanes yet. So yeah, that's when I became a Hurricanes fan, I fell in love that night pretty much.

Team success was another common reason why individuals originally became fans of their favorite teams. While such success did not necessarily have to be a Stanley Cup victory, many participants noted that key playoff victories or consistent regular season success had sparked their interest in their respective teams. Oliver and Jeff both mentioned the playoff run in 2001, when the Los Angeles (LA) Kings 
upset the favored Detroit Red Wings, as the reason they started to become highly identified Kings fans. Alex mentioned that, living in Nashville, he decided to become a Predators fan because the alternative professional sport in Nashville is the NFL's Tennessee Titans, who had had a long history of poor performance in the league, whereas the Predators had made the playoffs consistently. Jane noted the LA Kings' recent string of successes as a reason for her moving from a casual fan to a diehard: "I'd only been to a Kings game here or there but I've followed them casually and then I guess you can say I was a band wagoner in 2012 when they won the cup so I'll always remember that cup run. And I kinda never stepped off'"

Community impact and civic pride played a large role, in terms of socialization, for some participants. The participants who live local to their team felt pride in their city and were influenced to become fans of the hockey team because of its association with the city. Lightning fan Owen said: "It's like a real civic pride, proud of my area and all that. That's what being a fan of the Lightning is for me". Mark, who is a Sharks fan, especially felt civic pride, since the Sharks were San Jose's first and only major professional sport team. They did not have to be lumped in with Oakland or San Francisco and finally had a team to call their own:

It's a source of civic pride for San Jose because I guess we kind of have that chip on our shoulder that we're the little brother to Oakland and San Francisco and so it's like San Francisco has the Giants and the 49ers and Oakland has the Raiders and the A's and San Jose, south bay wasn't really known for a lot of sports because we didn't really have any. Then when the Sharks came we really attached to that. That's why if you ever make it out there you can understand why hockey works there - it's because they did a great job with taking root on the civic level.

Some others were hockey fans in general before picking an NHL team to root for and decided on their NHL team because they were local. An example is Jane, who attended an East Coast Hockey League game in Fort Wayne, Indiana, found she enjoyed the sport of hockey, and wanted to follow it at the major league level. So she picked the Kings because she is from Los Angeles. As well, Paige was a casual hockey fan when she lived in New York but when she moved to Arizona, she wanted to follow the NHL more and decided to become a Coyotes fan because they were local.

\section{Personal Influence}

There were various fan backgrounds for the parents of participants, but most cited their parents as individuals who influenced them to become a fan of their team. Parents of participants can be described as either originally from the Sunbelt region, originally from a more traditional hockey region (Northeast or Midwest region) and relocated to the Sunbelt, or never lived in the Sunbelt region. From there, parents either kept their allegiance to their old team after relocation, adopted the new team after relocation, became a fan of hockey along with or because of their child, or are not a fan of hockey at all. It was also fairly common to see parents of participants keep their allegiance to their original team while adopting the new local team as a secondary team, keep their original team as a secondary team, or claim they support both teams equally. Some, such as Amy, Daniel, and Austin, had parents who were originally from other regions of the country and had NHL allegiances before the Sunbelt teams existed but switched allegiances when the new team came into existence. Others, such as parents of James, Andrew, and Jeff, are from the Sunbelt region and they did 
not have a favorite team prior to the Sunbelt team existing. As well, there are some, such as parents of Paige, who maintain their fandom of a team from outside the region. Either way, all those individuals cited their parent's fandom as a factor that led to them becoming an NHL fan. They recalled watching games on television or attending games in person as early memories with their parent that influenced their fandom.

For some fans who did not have parents as an influence, they had siblings or friends that contributed to their socialization. Stephanie said her brother took her to her first Ducks game and she enjoys talking about the Ducks with him. Emily is a Sharks fan because her friends are season ticket holders and they started bringing her to games. Lightning fan Daniel noted his friends he grew up with as influential, similar to Kings fan Oliver who said:

I went to a bunch of different schools during that time and the school I settled in I made friends who was playing hockey and was interested in hockey so I started playing roller when I was about 12 . Then one of my best friends came to the school in fifth grade and it seemed like me and him were both Kings fans and there was some other people and then we started a roller hockey team at my school. So I guess that's kinda why I became interested in hockey moreso than any other sport because I associated with guys who liked hockey.

\section{Media Influence}

Along the lines of Frederiksen (2003), media exposure was found to be a common socialization agent among participants in this study. Frederiksen (2003) cited factors, such as 24 hour sport programming, as a reason media exposure was becoming a prominent socialization agent. However, it was found that participants rarely spoke about media exposure via television. Most of it was through online sources, mainly social media. Elizabeth noted that the Lightning's twitter account caught her attention and Paige spoke about the videos the Coyotes share through their social media as what endeared her to the team. Noah mentioned that when he subscribed to the NHL's online game streaming service NHL Game Center (now NHL.tv), his interest in the Stars began to rise and solidified him as a hardcore fan. Other forms of socialization media exposure included films and video games. Stephanie said she loved the Disney Mighty Duck film series, influencing her to become a Ducks fan, and Sharks fan Paul said his earliest exposure to the NHL was through the EA Sports NHL video game series:

"My mom when I was maybe 13 or 14, I never had like a gaming console growing up - I only had like the family computer. And on a whim she got me NHL 03 or 04 for PC and I started playing it and for whatever reason, I think I chose them because I liked the logo. I never really like knew anything or really paid attention to hockey before then and I just picked the Sharks and now I am a huge fan!”

\section{Fan Identity Maintenance}

Factors that contribute to the maintenance and strengthening of one's membership in their team's fandom included civic pride, attachment to the players, new friends made through the fandom, being a part of the NHL fan community, and introducing others to the sport, all of which were influential in the participants' continuing team identification. Civic pride, particularly for long-distance fans, was commonly 
mentioned as a reason for remaining a fan of a team. For example, Mark, a Sharks fan who lived overs eas for a number of years, was able to feel closer to home by discussing the team with family and friends over the phone. Upon returning to the U.S., Mark relocated to San Diego and enjoyed representing the Sharks in a different city:

"I'll go out on the town and I'll wear my Sharks jersey, or I'll wear a Sharks sweater or a ball cap or something like that, just because I'm proud of being from the Bay area and it's a piece of me. So really, I identify with it from being away from home."

Similarly, Amy, a Predators fan who moved from Nashville to Connecticut, explained: "I think the fact that I've been a fan outside of the region has really been a part of [my identity as a fan]. There's sort of a little level of pride there [in] being unusual". These experiences allowed Mark and Amy to solidify their fan status and led them to stronger levels of team identification.

An attachment to individual players was another common response when participants were asked what keeps them identified as fans. Kings fan Jane mentioned being a particularly big fan of defenseman Alec Martinez, having even purchased a jersey with his name on the back. This player was not an all-star player or a household name, but Jane identified with him strongly because she saw him as an underdog and felt that he deserved to have some fans, compared to the more popular players on the team. She said she really enjoyed getting to know the players on a more personal level through their reality TV show, which featured a behind-the-scenes look at the players' lives; Predators fan Amy and Ducks fan Stephanie also said they enjoyed this aspect. In short, not only star players who had endeared themselves to participants, but also regular players who fans felt they had gotten to know on a personal level through reality TV shows or social media led to the participants' attachment and contributed to their continued identification with the team.

Creating new friendships through team fandom was another common factor that carried fans from their original socialization to lifelong fan status. Predators fan Henry went out of state for college and met one of his best friends because of a mutual love of the Predators:

"Up here at school actually, the reason I found one of the other kids at college whose from Nashville is because I was wearing my Preds jersey one day and he was wearing his and we spotted each other on campus and I went up and met him and talked to him and now we're pretty good friends, it was pretty cool."

Hurricanes fan Joseph met new friends at games and tailgates, later meeting them regularly to watch Hurricanes games at bars when they were playing on the road. Another Hurricanes fan, Austin, bought a single season ticket but said he did not feel as if he was attending the games alone because he had met a lot of new friends who were also season ticket holders. It was not only at games that participants met new friends; the majority of them also mentioned friends they had made online and these friendships helped to solidify their fan status. Kings fan Jane said she first visited the online community Reddit to read articles and get news about the Kings. Eventually, she started posting her own comments and building relationships with other posters, whom she came to consider friends. Sharks fan Paul made friends through conversations about the Sharks on Twitter and these friendships later extended into other domains beyond hockey. These new friendships led to a sense of community, which was another common reason participants maintained their fan status; in essence, they enjoyed being part of the NHL fan culture. 
This fan culture often came up in conversation with participants and was a point of pride for most of them, because the NHL fandom felt like a unique, exclusive club to which they belonged. The NHL fan community was a very welcoming, inclusive, and exciting environment for them. NHL fans in the Sunbelt also experienced a feeling of distinctiveness, since it was less common to be a fan of the NHL in this region compared to the NFL, NASCAR, MLB, NBA, and NCAA. This uniqueness was a factor for participants that stretched beyond their own team's fandom. Coyotes fan Paige noted that the sense of camaraderie was somewhat unique to hockey: "I love hockey communities, because it seems like no matter what team you follow you can connect with hockey fans everywhere; whereas, with football, you don't really get that". Most participants pointed to the sense of belonging derived from the online community of NHL fans as being particularly influential in leading them to become more strongly identified as fans. Reddit, Twitter, and Tumblr were the online venues most often mentioned by participants. A major reason most participants turned to online communities was that their local communities lacked people who were as knowledgeable about the team as they were. Through these online communities, participants were able to develop a sense of belonging that they could not find in their residential communities. This sense of belonging was a very common sentiment shared by most participants and being a part of this unique fan culture was a prevalent theme in helping participants to maintain their fan status.

A large part of this hockey culture was the pleasure and excitement participants felt when inviting new people into this fan community with them. Almost every participant mentioned that he or she had influenced friends or family to become fans, most intentionally and some unintentionally. Stars fan Noah described how the idea of influencing others to join the community was ingrained into the culture of being an NHL fan: "Every good hockey fan evangelizes others to come". This type of common ground that NHL fans shared is built on a welcoming and inclusive environment that is touched on by Lightning fan Elizabeth: The community just for hockey as a whole has been very inclusive and very educational which is really nice. I know certain [groups], no matter what it is, whether it's a sport or like a game, or like a craft or a hobby, sometimes when you're new to something the community that surrounds that thing could either be very inclusive and welcoming, or they could be like oh you don't know what you're doing, you don't know what you're talking about and it kind of excludes someone or makes them feel unwanted - so that's been really wonderful.

Participants enjoyed getting others to become fans of the team; moreover, most felt that it was their responsibility as NHL fans to act as gatekeepers of the game and socialize others into the fandom.

\section{Discussion}

The findings revealed factors that contribute to forming the identity as a fan of a hockey team in a non-traditional hockey market. From the fans' perspective, first game experience, community impact, team success, media exposure, and influence of family and friends contributed to their initial socialization. Outcomes of their fan identity included civic pride, attachment to players, new friendships, membership in the NHL fan community, and socializing others. Together, these factors contributed to forming an individual's identity as a fan of his or her team. 
Building on previous literature that focuses on the socialization and outcomes of sport fandom, the current study has taken a further step in operationalizing fan socialization in geographic regions where a sport is new. Although the fans share of the socialization factors found in traditional socialization literature has been explored, such as influence from family and friends (McPherson, 1976; Wann \& James, 2018) and media exposure (Frederiksen, 2003), some new themes and patterns have also emerged in the current study. While the findings of this study show the important influence of family and friends, as identified in previous studies (McPherson, 1976; Wann and James, 2018) the form their influence takes differs. That is, instead of being influenced by friends at school or as a part of a long-standing family tradition, participants in this study were influenced by friends they met online through social media or by family members who were forming a new tradition together. The influence of media exposure was also found to be different from the finding identified by Frederiksen (2003) in that the participants were socialized through new media, such as podcasts or online streaming services, instead of more traditional forms of media, such as television and radio. In addition to expanding on previously identified themes, this study found that team success and first game experiencenot noted in previous literature as factors of the socialization process - emerged as factors equally important to the others.

With regards to maintaining his or her identity as a fan, key themes and patterns emerged through data collection. The factors that contribute to an individual maintaining their identity as a fan include civic pride, attachment to the players, new friends made through the fandom, being a part of the NHL fan community, and enjoyment derived from socializing others into the NHL fandom. These factors can be considered a part of the attachment and allegiance stage of Funk and James's (2001) Psychological Continuum Model. At this stage of one's development as a fan, individuals begin to recognize the benefits of being a fan and start to understand the collective, functional, and symbolic meaning of their fandom. According to Funk and James (2001), this stage is where the influence of socialization agents decreases and the internal process of their fandom becomes more important. This internal process leads to a larger impact in the decisions and behaviors of their fan identity. The key factor in maintaining fan identity, which is very important to the proposed model, is the enjoyment participants get in socializing with others. The idea that they not only enjoy introducing others to the game but also feel a responsibility to do so is a unique characteristic of NHL fans in the Sunbelt region. This process can be denoted as follows: Socialization into

Fandom $\rightarrow$ Solidifying and Maintaining Fandom $\rightarrow$ Socializing Others $\rightarrow$ Strengthening Fan Identity. The importance of the fan community and fans' active role in wanting to grow the sport creates an opportunity for this model to formulate and loop continuously to attract new fans and build a bigger fan base for the unique markets in the region.

\section{NHL Fan Culture}

Most fans felt pride in being NHL fans in general, enjoying their engagement with the NHL fan community at large, beyond their engagement with just fans of his or her own team. This is in line with Gwinner and Swanson's (2003) research on domain involvement, which pointed out how identification with the league as a whole can strengthen individuals' identification with their specific teams. Involvement with the sport or professional league as a whole could be of particular interest for fans of less successful or newer 
teams because associating their team with that domain allows them to maintain a positive attitude toward membership in the group without being solely associated with a particular team's poor win/loss record (Fisher \& Wakefield, 1998). Many fans felt that being an NHL fan was like being a part of a small and secret club. They are often in the minority in their communities, where identification with other sports such as football and baseball is much more common. Being an NHL fan thus feels like being a part of an exclusive club. These fans considered themselves to be a special part of the NHL's growth in the region. In fact, many felt protective of the sport, giving them a sense of responsibility to play their part in growing the league. Part of this responsibility was building a positive NHL fan community. This is one of the three key factors of Muniz and O'Guinn's (2001) branding community concept, namely moral responsibility to the brand. Such responsibility involves both integrating and retaining community members, in addition to assisting other members in the use of the brand. The data found in this study suggests that brand community is very important for fans of the NHL in the Sunbelt, which is supported by the findings from Mastromartino, Zhang, Hollenbeck, Suggs, and Connaughton (2019). Most participants described how much they enjoy being an NHL fan in general because of the unique culture of the NHL. Common factors contributing to this culture were the inclusive community, personable fans, and a common camaraderie with others as a result of being part of the unique, underdog, exclusive club of the NHL fandom.

Almost every participant said they had influenced someone else to become a fan and most participants mentioned a friend or family member as a major influence on their own fan identity. This stage of influencing others is key because once an individual has been socialized into the fandom and maintained his or her fan identity, he or she can begin to socialize others.

NHL teams in the Sunbelt region can make current fans happier, while creating a larger fan base, by finding ways to get current fans involved with the team and giving them the tools and access they need to socialize their friends and family into the team's fandom. Schau et al. (2009) noted that in this way, consumers become co-producers of the brand through their own behavior and thus become part of the brand community. However, research on brand communities and network theory suggests that the most important factor is not necessarily how many fans an organization can empower but rather who they empower specifically. Katz and Heere (2013) used social network analysis among fans of a newly formed sports team and found that the leader of each group of fans was crucial to the long-term attachment other fans developed toward the team. Their research findings "signify that not all members are created equal. A newly formed community is not a homogenous or random network of individuals but rather a network where a select few persons have many more connections, and thus a heightened importance, than the average consumer" (p. 283). This suggests that in a sport fan context, 'fan nations' are not simply groups of equally influential individuals; rather, they are made up of a smaller group of highly identified individuals with many connections to others whom they influence to become fans as well. In a follow-up study, Katz and Heere (2015) found that when leaders empowered other members of their group, this led to a stronger and more well-balanced fan group and thus, stronger team identification. These two studies provide a developmental outline for organizations to follow. The next step for team marketing managers is to identify the leaders, or key nodes, in the social network of their fan base and find ways to incorporate them in the brand development. 
Although the specific results from this case study cannot be generalized beyond the study parameter, this study does offer some practical implications and theoretical contributions for sport leagues outside of the NHL. These are especially applicable for leagues that are regionally popular but are still developing a geographical footprint in the United States or even beyond. Leagues such as the NHL, MLS, and NLL have rabid fan bases in certain pockets of North America but still fall in the shadow of the NFL, NBA, MLB, and NCAA. With the addition of a new NHL team in Las Vegas and the growth of smaller leagues in mind, some practical implications for sport managers can be drawn and theoretical contributions are made to the sport management field.

\section{Theoretical Contributions}

Although some of the results of the fan identity formation process found in this study are in line with previous studies (e.g., McPherson, 1976; Wann et al., 1996; Wann \& James, 2018; Zhang et al., 2001), this study makes a unique theoretical contribution regarding the role the fan community plays in socializing new fans. Previous socialization literature has made no mention of the fan community as an important socialization factor; however, in this study, the fan community was found to have a greater influence on socialization than some of the traditional factors (influence from peers, participation, etc.). Another contribution of note is importance of the fan community, which is unique in this context. Traditional elements of sport fan identify formation were found in this study, where parents, community, and friends played a large role in socialization. However, this study adds to theory the idea that organizations that are new or unconventional in their marketplace, such as the NHL in the Sunbelt, have to make greater efforts at the grassroots level than established teams. In these new markets, parents may be unfamiliar with the new team and may influence their children to socialize with teams into which they were socialized as children, before the new team existed. Moreover, new teams lack a long history and the list of important players in franchise history may be short, providing limited options for fan attachment. Thus, niche sport organizations attempting to grow their fan base cannot rely only on traditional identity formation processes but rather need to play a hands-on role in the socialization process and find unique ways to maintain fans' identification with the sport. From this study, it could be hypothesized that marketing strategies utilized, or not utilized, by the organization have a larger influence on fan identity formation for growing leagues in new markets as opposed to more established teams with a longer history.

In addition to providing a context-specific understanding of fan identification, the findings derived from this study considers cultural shifts in consumption behavior, adding to general theory on sport fans. Previous research has shown that individuals desire to be affiliated with like-minded people and align themselves with people and organizations that share values and beliefs similar to their own (Wann \& James, 2018). The results of this study take prior findings a step further by incorporating a modern consideration of how individuals foster these values and beliefs. While it is important that a sports team match the values and beliefs of the individual, it is also important for the individual to want to advocate on behalf of those values and beliefs and be a part of something bigger than a traditional fandom. The individual should want to be part of a movement to grow the brand of their favorite team and league, which in turn makes their fan identity more meaningful. This is especially the case for fans of nontraditional teams, since they have to work harder 
to maintain their fan identity when the identified sport is outside the realm of mainstream sports discourse. If fans of these teams feel that their team, as a representation of their values and beliefs, is in danger due to lack of popularity, they will go out of their way to influence others to become fans. Conversely, fans of established and popular leagues do not have to worry about their sport being in danger. With the increasing availability of communication technology, individual sport fans can have a voice they have never had before, leading to cultural movements and changing the landscape of fandom in North American professional sports.

\section{Conclusion and Future Research}

The findings of this study suggest that the fandom of NHL teams in the Sunbelt region can be broken down to a three-stage process. First, individuals become socialized into the fandom of a particular team through their first experience at a game, team success, media exposure, influence from parents, and influence from friends. In the second stage, the fans maintain and solidify their fan identity, often going outside the organization to do so. Factors that contribute to individuals' maintenance of their fandom include civic pride, attachment to players, new friends made through the fandom, membership in the NHL fan community, and introducing others to the sport. Being a part of the NHL fan community was a large positive for participants, to whom it felt like a secret and exclusive club for the underdogs of the professional sport world. Since introducing others to the sport is such a large part of the NHL fan culture, it constitutes the third stage of the process.

The challenging part of this process for NHL teams in the region will be to find a balance between maintaining the feeling of exclusivity and growing the fan base. A strength of this market is the solid brand community built by its fans; however, too much interference from teams building the fan community could be perceived as artificial or forced and thus have a negative impact on the fan community (Katz \& Heere, 2013). If a team's popularity grows, it may lose some of its underdog appeal; however, it remains in the best interest of the organization to grow its fan base. The NHL is on the rise in this region, and there are highly identified fans in these untraditional markets. This study shows examples of such fans and the passion they show through their involved fan activities, which go far beyond just catching an occasional game.

This study is culturally specific and may not be applicable to other regions where the NHL exists; thus, further research on this topic should be considered. First, it could be beneficial to conduct quantitative research to confirm the general themes and trends found in this study. It is a necessary next step to quantify each factor and examine which ones have the most significant impact on fan identity formulation. In addition, a further investigation of each individual market in this study could be beneficial in order to compare and contrast cities within the region and identify different ways in which fans operate, depending on the specific teams with which they identify. Because the NHL fandom is not a widely researched topic, it could also be beneficial to conduct research on the identity formation of fans in every market and region. This could provide insight on the league as a whole and add further insight to this study by comparing the Sunbelt with other regions.

Moreover, further research on the different types of parent fan identity and their influence on fans in this region could be conducted. The participants came from various fan backgrounds, such as those whose parents were originally from the Sunbelt region, those whose parents who were originally from a more 
traditional hockey region (Northeast or Midwest region) and had relocated to the Sunbelt, or those whose parents had never lived in the Sunbelt region. The participants' parents had either kept their allegiances to their old teams after relocation, adopted the new teams after relocation, became fans of hockey along with or because of their children, or were not fans of hockey at all. There could also be other ways to define parents' fan identity and further examination in this area could give organizations a better understanding of the role that parents play in socialization and how to work with parents in encouraging team identification among their children. Previous research has explored how parents have influenced their children into fandom (McPherson,1976; Parry, Jones, \& Wann, 2014; Wann, Tucker \& Schrader, 1996) and even how children have socialized their parents (Hyatt, Kerwin, Hoeber, \& Sveinson, 2018), but more research needs to be done on the role parents play in socialization when they themselves may not have a strong attachment to a new team in the region. In addition to this, further examinations into behavior in online fan communities is warranted. Due to this study recruiting participants from online communities, this study can be a launching pad for further investigations into how fans are socialized into and act in online sport fan communities. In brief, avenues for future research on the topic of the NHL fandom are plentiful and with the popularity of the sport growing and the start of a new expansion team in Las Vegas, there is much research to be done in the coming years. Future research can contribute greater understanding of NHL fans in order to help the league and teams continue to grow the game and their global brand. 


\section{References}

Competitive Intelligence. (2016), Retrieved June 26, 2016, from http://www.alexa.com/siteinfo/reddit.com

Cova, B., \& Pace, S. (2006). Brand community of convenience products: New forms of customer empowerment - the case "My Nutella The Community". European Journal of Marketing, 40, 1087-1105

Doyle, J. P., Lock, D., Funk, D. C., Filo, K., \& McDonald, H. (2017). 'I was there from the start': The identity-maintenance strategies used by fans to combat the threat of losing. Sport Management Review, 20(2), 184-197.

Fisher, R. J. \& Wakefield, K. (1998). Factors leading to group identification: A field study of winners and losers. Journal of Psychology \& Marketing, 15(1), 23-40.

Frederiksen, P. (2003). The relationship between sport fandom, identification with a specific team, and an individual's socialization experiences. Unpublished master's thesis, The University of Kentucky, Lexington, KY.

Funk, D. C., \& James, J. (2001). The psychological continuum model: A conceptual framework for understanding an individual's psychological connection to sport. Sport Management Review, 4(2), 119-250.

Gaines, C. (2013, November 08). Some U.S. cities may have too many pro sports teams. Retrieved November 07, 2017, from http://www.businessinsider.com/chart-some-us

Greenwell, T. C., Fink, J. S., \& Pastore, D. L. (2002). Assessing the influence of the physical sports facility on customer satisfaction within the context of the service experience. Sport Management Review, 5(2), 129-148. 
Gwinner, K., \& Swanson, S. R. (2003). A model of fan identification: Antecedents and sponsorship outcomes. Journal of Services Marketing, 17(3), 275-294.

Heere, B., \& James, J. D. (2007). Sports teams and their communities: Examining the influence of external group identities on team identity. Journal of Sport Management, 21(3), 319-337.

Hyatt, C. G., \& Foster, W. M. (2015). Using identity work theory to understand the deescalation of fandom: A study of former fans of National Hockey League teams. Journal of Sport Management, 29(4).

Hyatt, C. G., Kerwin, S., Hoeber, L., \& Sveinson, K. (2018). The reverse socialization of sport fans: How children impact their parents' sport fandom. Journal of Sport Management, 32(6), 542-554.

James, J. D. (2001). The role of cognitive development and socialization in the in itial development of team loyalty. Leisure Sciences, 23(4), 233-261.

Jenish, D. (2013). The NHL - A centennial history. Toronto, Canada: Random.

Katz, M., \& Heere, B. (2013). Leaders and followers: An exploration of the notion of scale-free networks within a new brand community. Journal of Sport Management, 27(4), 271-287.

Katz, M., \& Heere, B. (2015). Empowerment within brand communities: Overcoming the Achilles' Heel of scale-free networks. Sport Management Review, 18(3), 370-383.

Klein, J. (2011, February 20). Where hockey is growing, state by state. The New York Times.

Lock, D., Taylor, T., \& Darcy, S. (2011). In the absence of achievement: The formation of new team identification. European Sport Management Quarterly, 11(2), 171-192. 
Mastromartino, B. (2019). Understanding hockey fans and their consumption behaviors. In B.G. Pitts \& J. J. Zhang (Eds.), Sport Consumer Behavior Studies in the Global Context. London, UK: Routledge .

Mastromartino B., Zhang J.J., Hollenbeck C.R., Suggs D.W., Connaughton D.P. (2019). Conceptualizing sense of membership in a sport fan community. Journal of Sport Behavior, 42(3)

McPherson, B. D. (1976). Socialization into the role of sport consumer: a theory and causal model. Canadian Review of Sociology/Revue canadienne de sociologie, 13(2), 165-177.

Miles, M., Huberman, A., \& Saldana, J. (2014). Qualitative data analysis: A methods sourcebook ( $\left.{ }^{\mathrm{rd}} \mathrm{ed}.\right)$. Thousand Oaks, CA: Sage.

Muniz, A. M., \& O'Guinn, T. C. (2001). Brand community. Journal of Consumer Research, 27(4), 412432.

Parry, K., Jones, I., \& Wann, D. (2014). An examination of sport fandom in the United Kingdom: A comparative analysis of fan behaviors, socialization processes, and team identification. Journal of Sport Behavior, 37(3), 251-267.

Phua, J. J. (2010). Sports fans and media use: Influence on sports fan identification and collective selfesteem. International Journal of Sport Communication, 3(2), 190-206.

Rubin, H., \& Rubin, I. (2012). Qualitative interviewing: The art of hearing data. Thousand Oaks, CA: Sage.

Shamir, B., \& Ruskin, H. (1984). Sport participation vs. sport spectatorship: Two modes of leisure behavior. Journal of Leisure Research, 16(1), 9-21. 
Schau, H. J., Muñiz, A. M., \& Arnould, E. J. (2009). How brand community practices create value. Journal of Marketing, 73(5), 30-51.

Siggelkow, N. (2007). Persuasion with case studies. Academy of Management Journal, 50(1), 20-24.

Sutton, W. A., McDonald, M. A., Milne, G. R. \& Cimperman, J. (1997). Creating and fostering fan identification in professional sports. Sport Marketing Quarterly, 6(1), 15-22.

Tajfel, H. (1978). Social categorization, social identity and social comparison. In H. Tajfel (Ed.), Differentiation between social groups: Studies in the social psychology of intergroup relations (pp. 61-76). London, England: Academic.

Thomas, I. (2014). NHL COO John Collins talks league's revenue growth, plans for world cup of hockey. Sports Business Journal, 2014(11)

Tokuyama, S., \& Greenwell, T. C. (2011). Examining similarities and differences in consumer motivation for playing and watching soccer. Sport Marketing Quarterly, 20(3), 148-156.

Tracy, S. J. (2010). Qualitative quality: Eight "big-tent" criteria for excellent qualitative research. Qualitative Inquiry, 16(10), 837-851.

Trail, G. T., \& James, J. D. (2001). The motivation scale for sport consumption: Assessment of the scale's psychometric properties. Journal of Sport Behavior, 24(1), 108.

Underwood, R., Bond, E., \& Baer, R. (2001). Building service brands via social identity: Lessons from the sports marketplace. Journal of Marketing Theory and Practice, 9(1), 1-13.

Wann, D. L. (2006). The causes and consequences of sport team identification. Handbook of sports and media, 331-352. 
Wann, D. L., \& James, J. D. (2018). Sport fans: The psychology and social impact of fandom. London: Routledge.

Wann, D. L., Tucker, K. B., \& Schrader, M. P. (1996). An exploratory examination of the factors influencing the origination, continuation, and cessation of identification with sports teams. Perceptual and Motor Skills, 82(3), 995-1001.

Yin, R. (2003). Case study research: Design and methods ( $3^{\text {rd }}$ ed.). Thousand Oaks, CA: Sage.

Yoshida, M., Heere, B., \& Gordon, B. (2015). Predicting behavioral loyalty through community: Why other fans are more important than our own intentions, our satisfaction, and the team itself. Journal of Sport Management, 29(3), 318-333.

Zhang, J. J., Pease, D. G., Lam, E. T. C., Pham, U. L., Bellerive, L. M., Lee, J. T., Williamson, D. P., \& Wall, K. A. (2001). Socio-motivational factors affecting spectators to attend minor league hockey games. Sport Marketing Quarterly, 10(1), 43-56. 


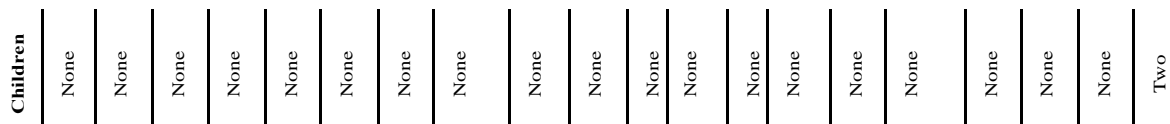

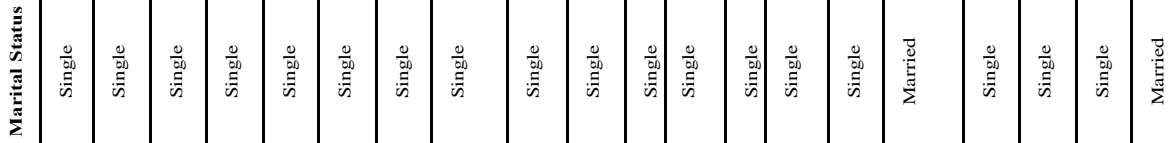

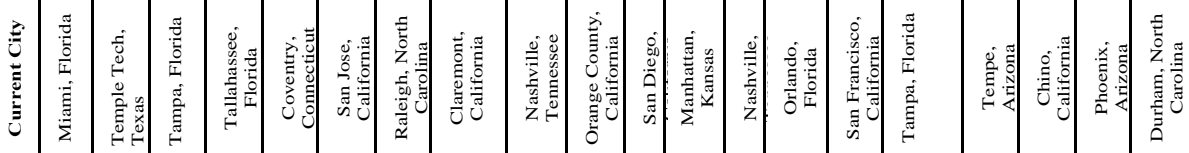

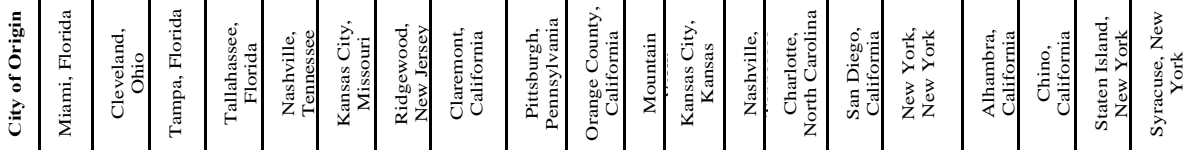

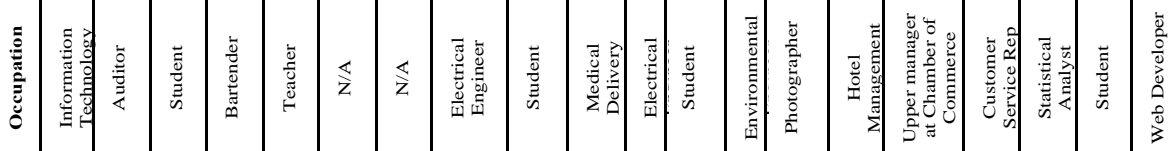

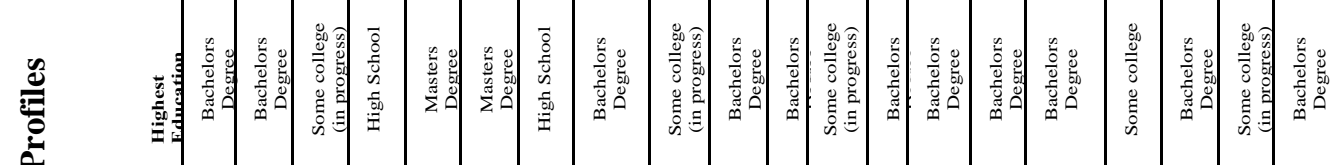

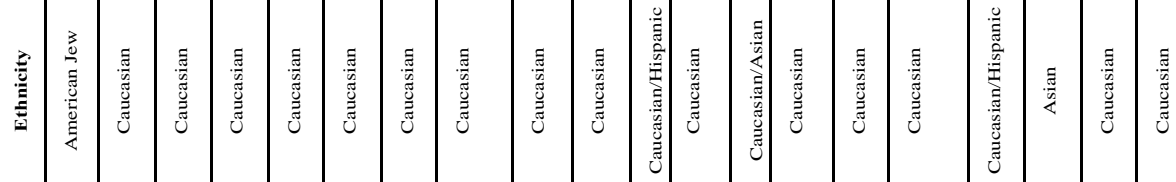

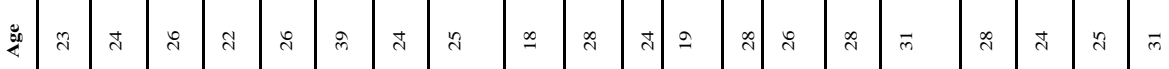

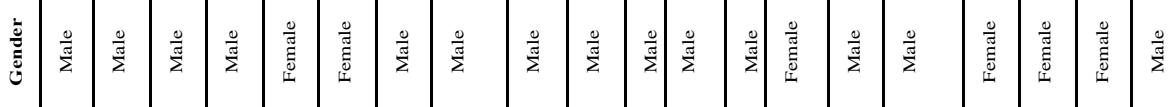

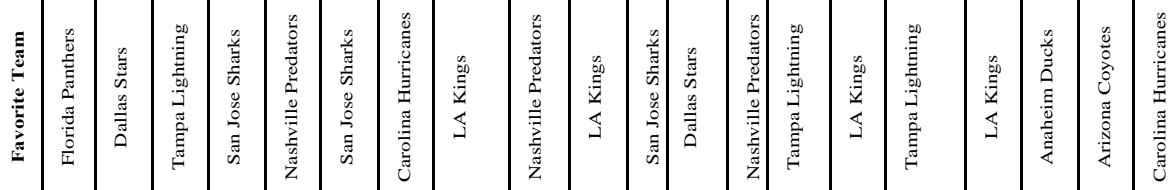

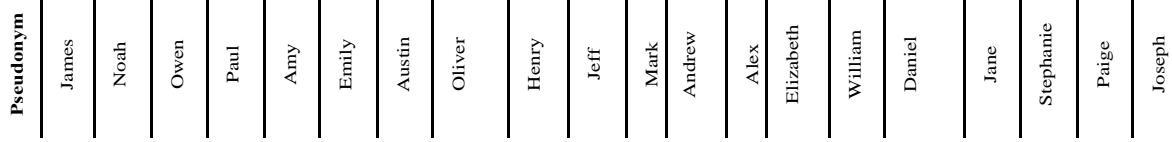

